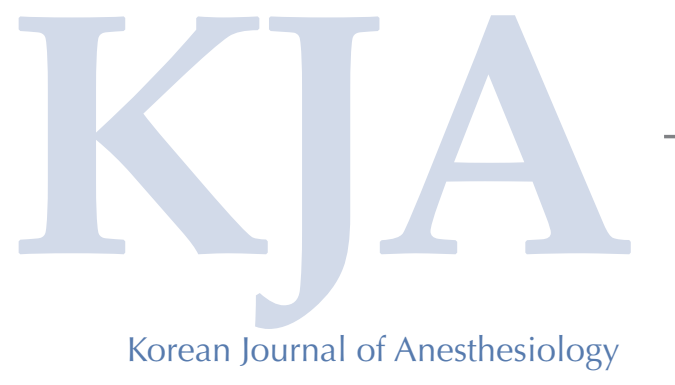

\title{
Limitations of spinal cord stimulation for pain management
}

\author{
Jae Hang Shim \\ Department of Anesthesiology and Pain Medicine, Guri Hospital, Hanyang University School of Medicine, Guri, \\ Korea
}

As mentioned before [1], the spinal cord stimulation is very useful treatment modality for intractable pain. The spinal cord stimulator (SCS) has been applied for the treatment of pain associated with many different disease entities, including intractable pain, headache, and angina pain. It has also been applied for non-pain-related conditions such as congestive heart failure, ischemic peripheral vascular disease, interstitial cystitis, intractable spasticity, and cerebral vasospasm after subarachnoid hemorrhage [2-6].

In a previous issue of the Korean journal of anesthesiology, Lee et al. [7] described the pain management during a procedure for permanent spinal cord stimulation with a cylindrical type lead insertion. They mentioned that implantation of a permanent SCS system is painful and intolerable in some patients. Therefore they attempted to perform the procedure under epidural anesthesia. SCS systems are composed of three components: leads/electrodes, a generator/power source, and a programmer/ controller [8]. The leads can be divided into percutaneous leads and paddle leads. When pain physicians use percutaneous cylindrical type leads, procedure is usually performed under local anesthetic infiltration. However, actually many patients complain of pain or discomfort during SCS device implantation because they have existing severe pain that make worse. This case report suggests that epidural anesthesia is a good choice for reducing pain and ensuring safety during establishment of permanent spinal cord stimulation with percutaneous cylindrical type lead insertion.

Many pain physicians, myself included, believe that the spinal cord stimulation is a lamp of hope for patients with intractable

\footnotetext{
Corresponding author: Jae Hang Shim, M.D., Ph.D.

Department of Anesthesiology and Pain Medicine, Guri Hospital, Hanyang University School of Medicine, 153, Gyeongchun-ro, Guri 471-701, Korea

Tel: 82-31-560-2390, Fax: 82-31-563-1731

E-mail: jhshim@hanyang.ac.kr
}

Korean J Anesthesiol 2015 August 68(4): 321-322 http://dx.doi.org/10.4097/kjae.2015.68.4.321 pain. However, some limitations confound our endeavors. Mekhail et al. [9] reported indications and complications of SCS in 707 cases with discussion. The reported complication rate ranges from 30 to $40 \%$. The lead migration rate is $22.6 \%$, the lead connection failure rate is $9.5 \%$, and lead breakage rate is $6.0 \%$. Lead migration complication is more frequent with percutaneous than paddle-type electrodes $[3,5]$. Infection was reported in $4.5 \%$ of patients and pain at the generator site in $12.0 \%$ of patients. Other complications include bleeding, paresthesia, and dural puncture $[2,4,6]$. Hardware related problems, such as lead failure, migration, and device malfunction, are more common than infection [10]. Complications may be avoided or at least diminished by performing a proper and strict aseptic surgical technique as well as regular checks and continuous follow-up [5]. Hayek et al. [11] reported the long-term implant survival rate and complications of SCS. The complication rate was $34.6 \%$, and hardware related complications were the most common type of complications among 234 cases. The revision and explantation rates were both $23.9 \%$. The most common reason for explantation was loss of the therapeutic effect. Although the rate of serious complications was low, the rate of overall complications remained relatively high in that study. The authors concluded that a greater effort is needed to decrease complication rates in the future, which will increase patient satisfaction and decrease medical costs.

Other problems involve the perioperative evaluation and management of patients with spinal cord stimulator [12]. Performing magnetic resonance imaging (MRI) with SCS implanted patients is harmful and restricted because of heating of SCS and injuring the patient. MRI-safe SCS device is important for patients with spinal origin pain, particularly for management of postlaminectomy syndrome. Monopolar electrocautery is also generally not recommended for patients with SCS because of the risk of thermal injury to the tissue in contact with the SCS. Therefore, bipolar electrocautery is recommended when cautery is necessary. The most important factor for minimizing risks regarding SCS implanted patients is increasing physician awareness. Young et al. [13] reported the management of pregnant

(c) This is an open-access article distributed under the terms of the Creative Commons Attribution Non-Commercial License (http://creativecommons.org/ licenses/by-nc/4.0/), which permits unrestricted non-commercial use, distribution, and reproduction in any medium, provided the original work is properly cited. 
women with SCS implantation. Seven patients underwent implantation of SCS before becoming pregnant. Data on these patients before, during, and after labor were collected. Four general anesthetics and three neuraxial anesthetics were administered for cesarean delivery. All infants and mothers were healthy after delivery. They mentioned that interventional pain physicians have to consider future pregnancy as an issue in treating young women with complex regional pain syndrome.

Some patients with SCS have comorbid diseases such as cardiovascular problems. The incidence of patients with cardiac disease has recently increased, and numerous implantable cardioverter-defibrillators (ICD) are now being used to treat potentially life-threatening cardiac arrhythmias. Chaiban et al. [14] reported electromagnetic interaction between SCS and lifesaving ICD. Although there were some limitations in their study, they demonstrated that there was no interaction between the two devices at various settings. However, physicians need to confirm the safety and interaction between SCS and ICD during implantation of the SCS in patient who already have an ICD device.

Many engineers and machinery companies are focusing much effort on developing new equipment. The multi-channel device with multi-polar small sized leads, integrated accelerometer, embedded gyroscope, sensing feedback technology and MRI safe device may promise to increase efficacy and decrease limitations and device-related complications of SCS in the near future [15]. Bioengineering, including advancement of SCS technology and mechanism, should help to liberate patients from pains and aches.

\section{References}

1. Shim JH. Spinal cord stimulation: panacea for incurable diseases? Korean J Anesthesiol 2013; 65: 103-4.

2. Towers WS, Ding YR, Kurtom KH. Delayed upper extremity paresthesia post permanent implantation of five lead spinal cord stimulator for low back and lower extremity pain: a case report. Clin Neurol Neurosurg 2015; 134: 72-4.

3. Gazelka HM, Freeman ED, Hooten WM, Eldrige JS, Hoelzer BC, Mauck WD, et al. Incidence of clinically significant percutaneous spinal cord stimulator lead migration. Neuromodulation 2015; 18: 123-5.

4. Buvanendran A, Young AC. Spinal epidural hematoma after spinal cord stimulator trial lead placement in a patient taking aspirin. Reg Anesth Pain Med 2014; 39: 70-2.

5. Bendersky D, Yampolsky C. Is spinal cord stimulation safe? A review of its complications. World Neurosurg 2014; 82: 1359-68.

6. Kunnumpurath S, Srinivasagopalan R, Vadivelu N. Spinal cord stimulation: principles of past, present and future practice: a review. J Clin Monit Comput 2009; 23: 333-9.

7. Lee SE, Choi RM, Kee R, Lee KH, Jeon S, Jung JW, et al. Epidural anesthesia for permanent spinal cord stimulation with a cylindrical type lead: a case series. Korean J Anesthesiol 2015; 68: 179-83.

8. Epstein LJ, Palmieri M. Managing chronic pain with spinal cord stimulation. Mt Sinai J Med 2012; 79: 123-32.

9. Mekhail NA, Mathews M, Nageeb F, Guirguis M, Mekhail MN, Cheng J. Retrospective review of 707 cases of spinal cord stimulation: indications and complications. Pain Pract 2011; 11: 148-53.

10. Zan E, Kurt KN, Yousem DM, Christo PJ. Spinal cord stimulators: typical positioning and postsurgical complications. AJR Am J Roentgenol 2011; 196: 437-45.

11. Hayek SM, Veizi E, Hanes M. Treatment-limiting complications of percutaneous spinal cord stimulator implants: a review of eight years of experience from an academic center database. Neuromodulation 2015 [Epub ahead of print]

12. Walsh KM, Machado AG, Krishnaney AA. Spinal cord stimulation: a review of the safety literature and proposal for perioperative evaluation and management. Spine J 2015 [Epub ahead of print]

13. Young AC, Lubenow TR, Buvanendran A. The parturient with implanted spinal cord stimulator: management and review of the literature. Reg Anesth Pain Med 2015; 40: 276-83.

14. Chaiban GM, Cummings J, Almualim M, Atallah J. Evaluation of interaction between a spinal cord stimulator and implanted cardioverterdefibrillator in a swine model. Pain Physician 2013; 16: 489-96.

15. Levy RM. Spinal cord stimulation in 2020. Neuromodulation 2013; 16: 93-6. 